\title{
CARACTERÍSTICAS DO PARTO E INVOLUÇÃO UTERINA EM OVELHAS NATIVAS DO PANTANAL BRASILEIRO
}

\author{
Carlos E. Fernandes ${ }^{1}$, Cristiane FABIANe Cigerza ${ }^{2}$, Guilherme dos SANTOS Pinto ${ }^{3}$, Cesar \\ MiAZI $^{4}$, MARCOS BARBosA-FERREIRA ${ }^{4}$, CHARlES FERREIRA MARTINS ${ }^{5}$ \\ ${ }^{1}$ Professor Adjunto, Centro de Ciências Biológicas e da Saúde, Universidade Federal do Mato Grosso do Sul, \\ Campo Grande, MS, Brasil. carlos.fernandes@ufms.br \\ ${ }^{2}$ Programa de Pós-graduação em Ciência Animal, FAMEZ, Universidade Federal do Mato Grosso do Sul, Campo \\ Grande, MS, Brasil \\ ${ }^{3}$ Medico Veterinário Autônomo, Campo Grande, MS, Brasil. \\ ${ }^{4}$ Centro Tecnológico para Ovinocultura, Faculdade UNIDERP/Anhanguera, Campo Grande, MS, Brasil. \\ ${ }^{5}$ Professor Doutor da Universidade Federal de Pelotas, Pelotas, RS, Brasil.
}

O objetivo deste estudo foi descrever aspectos do parto e da involução uterina em ovelhas nativas do Pantanal. Foram estudadas 57 fêmeas pluríparas com cio sincronizado. Ao parto, avaliou-se sua classificação (simples ou gemelar), o tempo de expulsão da placenta, peso da placenta, total de diâmetro dos cotilédones, além do sexo e peso do cordeiro. A involução uterina foi avaliada pelo perfil leucocitário e de células de descamação (esfregaços cérvico-uterinos) e pela ultrassonografia uterina transretal nos dias 1, 7, 14, $21 \mathrm{e}$ 28 dias pós-parto. O peso da placenta foi superior $(\mathrm{P}<0,05)$ nas fêmeas nascidas tanto dos partos simples quanto nos gemelares seguido pelo total de cotilédones. $\mathrm{O}$ tempo de expulsão da placenta e diâmetro dos cotilédones não diferiu $(\mathrm{P}<0,05)$ entre o sexo e parto. Os períodos 1,7 e 14 dias pós-parto apresentaram valores superiores $(\mathrm{P}<0,05)$ para neutrófilos nos partos gemelares $(78,5 \pm 9,5$; $58,5 \pm 9,6$ e $31,9 \pm 9,8$, respectivamente). Macrófagos diferiram $(\mathrm{P}<0,05)$ nos períodos 1 e 14 para fêmeas com partos gemelares $(12,5 \pm 1,6$ e $6,7 \pm 1,6$, respectivamente). A análise da regressão revelou ajuste quadrático $(\mathrm{P}<0,001)$ para o diâmetro, área e volume uterinos considerando todo o período pós-parto. As características observadas ao parto nas ovelhas nativas são semelhantes a ovelhas de outras raças. $\mathrm{O}$ perfil leucocitário e análise ultrassonográfica sugerem que a involução uterina nas ovelhas nativas do Pantanal varia entre 14 e 21 dias após o parto.

PALAVRAS-CHAVE: leucócitos; ovinos; parto; período pós-parto; ultrassonografia.

\section{PARTURITION CHARACTERISTICS AND UTERINE INVOLUTION IN NATIVE SHEEP FROM BRAZILIAN PANTANAL}

\section{ABSTRACT}

The aim of this study was to describe aspects of the parturition and uterine involution in native sheep from Brazilian Pantanal. Fifty-seven pluriparous ewes were used in this study. At parturition, the placenta expulsion (h), weight $(\mathrm{g})$, total diameter of cotyledons, sex and weight of newborn, and single or twin parturition were evaluated. The uterine involution was evaluated by leucocytes profile, desquamation cells (cervix-uterine smears) and transrectal ultrasonography at 1, 7, 14, 21 and 28 days post-partum. The weight of the placenta and total of cotyledons were higher $(\mathrm{P}<0.05)$ in female lambs from single and twin parturition. Placental expulsion time and cotyledons diameter were not different $(\mathrm{P}>0.05)$ between sex and parturition classification. The total of neutrophils in twin parturitions were higher in days 1,7 and 14 postpartum $\quad(78.5 \pm 9.5 ; \quad 58.5 \pm 9.6$ and 31.9 \pm 9.8 , respectively). Macrophages were different $(\mathrm{P}<0.05)$ at 1 and 14 days postpartum in ewes with twin parturition (12.5 \pm 1.6 and $6.7 \pm 1.6$, respectively). The regression analysis model revealed a quadratic curve estimation $(\mathrm{P}<0.001)$ to the diameter, area and uterine volume considering all postpartum period. In conclusion, the parturition characteristics are similar to other breeds. Leukocytary profile and the transrectal ultrasonography 
exam suggest that the uterine involution in native sheep of Brazilian Pantanal varies among 14 and 21 days

postpartum.

KEYWORDS: leukocytes; ovine; parturitium; postpartum period; ultrasonography.

\section{INTRODUÇÃO}

Estima-se que os ovinos foram introduzidos na região pantaneira juntamente com o gado bovino de origem europeia, há quase três séculos, pelos colonizadores portugueses e espanhóis, vindos da bacia platina e Paraguai. Estes animais, originalmente de clima temperado, após se adaptarem às condições do meio ambiente local, de características tropicais, vieram a formar o tipo crioulo denominado Tucura ou Pantaneiro (CORREA FILHO, 1926 citado por ROSA et al., 2007). Assim como os bovinos, os ovinos se adaptaram aos poucos cuidados de manejo sendo mantidos quase que exclusivamente em pastagens nativas das extensas planícies arenosas e com poucas subdivisões, de forma a permitir o pastejo seletivo e o uso das aguadas (GARCIA, 1986). Os ovinos nativos do Pantanal compõem um grupamento genético cruzado, sem raça definida, mas plenamente adaptados às condições regionais com predominância europeia (McMANUS et al., 2005; SANTOS et al., 2010). Porém, diversos aspectos da fisiopatologia da reprodução ainda não são conhecidos e consistem em desafios para aumentar os índices reprodutivos.

Para a produção de ovinos de forma intensiva, o período pós-parto pode ser considerado como crítico para a continuidade da função reprodutiva das fêmeas. Nesse período, o útero retoma o tamanho, posição e tônus necessários para uma nova gestação, em resposta à interação do eixo hipotálamo-hipófise-gônadas. Imediatamente após o parto, o conteúdo uterino é prontamente expulso em função da atividade contrátil endometrial devido aos níveis elevados de prostaglandina $\left(E_{2}\right.$ e $\left.F_{2 \alpha}\right)$ e estradiol $17_{\beta}$ (THORBURN et al., 1991; BARTLEWSKI et al., 2000). Esse período, conhecido como puerpério, varia de 23 a 35 dias nas ovelhas, mas também pode chegar até 10 semanas com substancial redução nas taxas de concepção (Van WYK et al., 1972; KIRAKOFE, 1980).

Durante a primeira semana pós-parto, a vasculatura que irriga os placentônios degenera, resultando na formação do lóquio uterino, um exsudato denso de cor marrom produzido pela autólise das hemácias endometriais, associado à dissolução das lâminas fetais e maternas dos placentônios e expulsão de restos cotiledonares. (Van WYK et al., 1972). Na segunda semana, placas necróticas são liberadas da involução caruncular sendo que o lóquio torna-se menos denso e mais transparente. A reepitelização da região caruncular ocorre durante a terceira ou quarta semana pós-parto, simultaneamente ao decréscimo do tamanho e comprimento uterino (O'SHEA \& WRIGHT, 1984).

Embora os efeitos das infecções uterinas sobre o período pós-parto nos ovinos seja conhecido (TZORA et al., 2002), o perfil leucocitário, bem como outros indicadores fisiopatológicos tem sido pouco explorados durante a involução uterina em fêmeas sadias, especialmente nas nativas pantaneiras. Estima-se que as mudanças fisiológicas observadas no ambiente uterino estejam, em parte, interagidas com a população leucocitária e tônus muscular, em resposta à atividade lútea (GOTTSHAL \& HANSEN, 1992; HAYDER \& ALI, 2008). Dessa forma, a avaliação de indicadores da função uterina, incluindo o perfil imunológico celular e ultrassonográfico no pós-parto, permite acrescentar subsídios ao diagnóstico clínico, assim como o prognóstico da fertilidade potencial da fêmea, especialmente em sistemas intensivos de produção. Este estudo teve como objetivo estabelecer alguns parâmetros de importância clínica do parto e da e involução uterina em ovelhas nativas do Pantanal brasileiro.

\section{MATERIAL E MÉTODOS}

Foram selecionadas 57 fêmeas provenientes de fazendas do pantanal sul-matogrossense, com idade superior a dois anos, pluríparas com peso médio de $39,5 \pm 5,20 \mathrm{~kg}$ e condição corporal variando entre 2,5 a 3 (RUSSEL et al., 1969). As fêmeas foram mantidas no Centro Tecnológico de Ovinocultura (Universidade Anhanguera, Fazenda Três Barras, Campo Grande, MS). Todas as fêmeas foram consideradas aptas mediante exame ginecológico completo (HAIBEL, 1990; SHARKEY et al., 2001). Com o objetivo de concentrar o período de parição, todas as fêmeas foram submetidas à sincronização do 
cio, mediante implantação de pessários intravaginais de progesterona $(0,33 \mathrm{~g}$ progesterona, Eazi-Breed CIDR) por 06 dias, com aplicação de 200 a 300 UI de eCG (equine chorion gonadotropin) no quinto dia e monta dirigida (machos nativos do Pantanal com fertilidade comprovada) mediante apresentação de cio (DIAS et al., 2001).

Próximo ao parto, as fêmeas foram mantidas em local protegido com água e pasto $a d$ libitum. Mediante observação dos primeiros sinais clínicos do parto, a fêmea era separada do grupo, pesada e mantida sob constante observação. Em seguida após o parto, registrou-se o tempo (horas) de eliminação e peso da placenta, sexo e peso do cordeiro, assim como o tipo de parto (simples ou gemelar). Em relação à placenta, foram anotados o total de cotilédones e o diâmetro médio de dez estruturas observadas aleatoriamente.

As análises pós-parto foram realizadas consecutivamente nos dias 1, 7, 14, 21, e 28. Em cada um desses períodos, as fêmeas foram submetidas a exame ginecológico vaginal e ultrassonográfico transretal. Amostras cérvicouterinas (swabs) foram colhidas e imediatamente estendidas em lâminas fixando-as com metanol. Posteriormente, as lâminas foram coradas, com solução Panóptica (ciclohexadieno $0,1 \%$, azobenzenosulfônicos $0,1 \%$ e fenotiazina $0,1 \%$ ). A leitura foi realizada em 15 campos aleatórios (microscopia de campo claro, 400x), considerando o total de neutrófilos, macrófagos, linfócitos, eosinófilos e células de descamação. A ultrassonografia transretal (Pie Medical com transdutor linear de 8,0 Mhz) foi usada para mensurar o diâmetro $(\mathrm{cm})$, área $\left(\mathrm{cm}^{2}\right)$ e volume $\left(\mathrm{cm}^{3}\right)$ do útero.

As variáveis obtidas após o parto (tempo de eliminação da placenta, peso do cordeiro, total e diâmetro cotiledonário) foram submetidas à análise de variância, modelo linear ao acaso com efeito principal e interativo entre sexo e tipo de parto. Células leucocitárias e de descamação foram comparadas entre os períodos pós-parto ( 1 até 28 dias) pela análise de variância, modelo linear para medidas repetidas de acordo com o tipo de parto. $\mathrm{O}$ modelo de regressão linear simples foi usado para estimar as variações do diâmetro, área e volumes uterinos de acordo com o período pósparto.

Esta proposta foi aprovada pela Comissão de Pesquisa da UFMS (projeto $\mathrm{n}^{\circ}$ 2009/0110, parecer 312/09), de acordo com a Resolução
879/2008 do CFMV.

\section{RESULTADOS E DISCUSSÃO}

Embora os ovinos nativos do Pantanal sejam considerados sem raça definida, apresentam características fenotípicas semelhantes com resistência, funcionalidade e rusticidade adaptadas às condições da região, além de apresentarem variabilidade genética interessante do ponto de vista da conservação de germoplasma (MARIANTE et al., 2011). Isso tem despertado interesse em conhecer melhor as condições produtivas dos rebanhos bem como o potencial para adequação de técnicas de manejo sustentável às criações (SANTOS et al., 2010).

Os resultados das variáveis observadas ao parto estão descritos na Tabela 1. De forma geral, esses achados são semelhantes aos reportados para outras raças ovinas embora sejam originais para ovelhas nativas do Pantanal. No entanto, provavelmente são superiores aos observados nas criações extensivas dessa região, já que os animais receberam manejo sanitário e nutricional adequados à categoria reprodutiva, além de terem sido manejados em um centro tecnológico de criação. Um exemplo desse aspecto foi a taxa de partos gemelares, nitidamente incrementada, supostamente pelo efeito nutricional ou ainda pelo emprego da sincronização do cio e partos concentrados (NAQVI et al., 2001; MORI et al., 2006). Do total de partos observados, $38(66,6 \%)$ foram simples e $19(33,3 \%)$ gemelares, resultando em 76 cordeiros, sendo 39 (51,3\%) machos e 37 $(48,7 \%)$ fêmeas.

O tempo médio de expulsão da placenta foi superior a três horas, na maioria das fêmeas, independente do tipo de parto e sexo do recémnascido. Esse resultado contrasta com o de ARTHUR (1979), que relatou um período de uma a, no máximo, três horas tanto nos partos simples quanto nos gemelares. Essa diferença pode estar de acordo com a origem genética dos animais, ou seja, pelo efeito das diferentes raças que compõem as ovelhas nativas (McMANUS et al., 2010). Além disso, o peso e o tamanho da fêmea, a sincronização do cio, a genética paterna e a ordem de parto podem interferir nesse resultado (KEISLER, 2007). Por outro lado, o tempo de expulsão da placenta não apresentou correlação com as demais variáveis estudadas ao parto (Tabela 2), corroborando com estudos que demonstram que essa relação só se confirma nos 
casos de severa infecção uterina com retenção placentária (TZORA et al., 2002; HINDSON \& WINTER, 2007). Neste estudo, contudo, nenhuma fêmea apresentou retenção de placenta ou infecção uterina puerperal.

Tabela 1. Médias ajustadas ( \pm epm) para variáveis observadas ao parto em ovelhas nativas do Pantanal sulmato-grossense, submetidas à sincronização de cio e parição concentrada

\begin{tabular}{lcccc}
\hline \multirow{2}{*}{ Variáveis } & \multicolumn{2}{c}{$\begin{array}{c}\text { Simples } \\
(\mathrm{n}=38)\end{array}$} & \multicolumn{2}{c}{$\begin{array}{c}\text { Gemelar } \\
(\mathrm{n}=19)\end{array}$} \\
\cline { 2 - 5 } & $\begin{array}{c}\text { Macho } \\
(\mathrm{n}=20)\end{array}$ & $\begin{array}{c}\text { Fêmea } \\
(\mathrm{n}=18)\end{array}$ & $\begin{array}{c}\text { Macho } \\
(\mathrm{n}=19)\end{array}$ & $\begin{array}{c}\text { Fêmea } \\
(\mathrm{n}=19)\end{array}$ \\
\hline Tempo expulsão da placenta $(\mathrm{h})$ & $3,3 \pm 0,18^{\mathrm{a}}$ & $3,4 \pm 0,19^{\mathrm{a}}$ & $3,3 \pm 0,19^{\mathrm{a}}$ & $2,9 \pm 0,20^{\mathrm{a}}$ \\
Peso da placenta $(\mathrm{g})$ & $407,1 \pm 54,24^{\mathrm{a}}$ & $471,4 \pm 56,42^{\mathrm{b}}$ & $502,4 \pm 56,00^{\mathrm{b}}$ & $547,5 \pm 62.21^{\mathrm{c}}$ \\
Total de cotilédones & $74,4 \pm 4,0^{\mathrm{a}}$ & $65,3 \pm 4.6^{\mathrm{b}}$ & $91.5 \pm 4.2^{\mathrm{c}}$ & $86.2 \pm 5.0^{\mathrm{c}}$ \\
Diâmetro dos cotilédones $(\mathrm{cm})$ & $17,2 \pm 1,5^{\mathrm{a}}$ & $17,7 \pm 1,7^{\mathrm{a}}$ & $21,1 \pm 1,6^{\mathrm{a}}$ & $21,7 \pm 1,9^{\mathrm{a}}$ \\
Peso do cordeiro $(\mathrm{Kg})$ & $3,7 \pm 0,13^{\mathrm{a}}$ & $3,7 \pm 0,13^{\mathrm{a}}$ & $2,6 \pm 0,13^{\mathrm{b}}$ & $2,5 \pm 0,15^{\mathrm{b}}$ \\
\hline
\end{tabular}

\pm erro padrão da média; ${ }^{\text {a,b,c }}$, indica efeito significativo $(\mathrm{p}<0,05)$ de parto e sexo dos cordeiros.

Tabela 2. Análise da correlação (modelo de Pearson) para as variáveis obtidas após o parto de ovelhas nativas do Pantanal sul-mato-grossense

\begin{tabular}{lcccc}
\hline Variáveis & $\begin{array}{c}\text { Peso da } \\
\text { placenta }(\mathrm{g})\end{array}$ & $\begin{array}{c}\text { Total de } \\
\text { cotilédones }\end{array}$ & $\begin{array}{c}\text { Diâmetro dos } \\
\text { cotilédones }(\mathrm{cm})\end{array}$ & $\begin{array}{c}\text { Peso do } \\
\text { cordeiro }(\mathrm{Kg})\end{array}$ \\
\hline Tempo de expulsão da placenta $(\mathrm{h})$ & $-0,13$ & $-0,16$ & 0,02 & 0,08 \\
Peso da placenta $(\mathrm{g})$ & - & $-0,06$ & $0,56^{* *}$ & $-0,01$ \\
Total de cotilédones & - & - & $-0,25^{*}$ & $-0,04$ \\
Diâmetro de cotilédones & - & - & - & $0,21^{*}$ \\
\hline
\end{tabular}

$* \mathrm{p}<0,05 ; * * \mathrm{p}<0,01$

A correlação observada entre peso da placenta e diâmetro dos cotilédones sugere aumento na área vascular, possivelmente oriunda do grupo de ovelhas com gestação gemelar que apresentaram placentas mais pesadas. Nesse grupo, o total de cotilédones observados foi maior em comparação ao grupo de fêmeas com gestação simples. Esses aspectos demonstram que a vasculatura da placenta ovina se adapta ao tipo de gestação podendo variar entre fêmeas da mesma raça (PENNINGAA \& LONGOB, 1998; SHOENAU et al., 2005).

As médias e respectivos desvios dos leucócitos e células de descamação observadas até 28 dias pós-parto estão descritos na Figura 1. Após a expulsão da placenta, o útero continua o processo de contração pelo efeito do estrógeno e prostaglandina $\mathrm{F} 2_{\alpha}$ sobre o miométrio. No entanto, a abertura momentânea da cérvice favorece a entrada de bactérias levando a uma resposta imune celular imediata (SHELDON, 2004). Além da infecção naturalmente desenvolvida, o endométrio inicia um processo regenerativo, paralelo à eliminação de grande quantidade de exsudato mucoso uterino (O'SHEA \& WRIGHT, 1984). O perfil leucocitário observado demonstrou que, do primeiro ao sétimo dia pós-parto, essa resposta foi mais marcante nas fêmeas com parto gemelar, caracterizado pelo aumento significativo de neutrófilos e macrófagos, em contraste ao perfil linfocitário. Essa resposta parece estar relacionada com a maior área uterina, porém sugere que seja de carácter fisiológico de acordo às modificações do ambiente intrauterino, estando diretamente associada à fagocitose das estruturas placentárias remanescentes pós-parto (NASAR et al., 2002). Ovelhas com parto simples reduziram os percentuais leucocitários mais precocemente, supondo um processo regenerativo mais rápido com prováveis benefícios na involução 
uterina. O perfil das células de descamação foi contrário ao leucocitário, com médias superiores aos 28 dias pós-parto. Esse achado possivelmente se deve a atividade endometrial proliferativa nesse período, em concordância com a reorganização da estrutura endometrial e endócrina do aparelho reprodutivo. De acordo com O'SHEA \& WRIGHT (1984), aos 23 dias pós-parto, ainda há presença de placas degenerativas de tecido placentário junto às carúnculas uterinas acompanhadas de células epiteliais. Esse aspecto é reiterado por GRAY et al. (2003) que evidenciaram proliferação da camada endometrial até o vigésimo oitavo dia pós-parto.

As análises ultrassonográficas resultaram em ajustes quadráticos para o diâmetro, área e volume uterinos (Figura 2). No entanto, nas ovelhas de parto gemelar, as mensurações mostraram-se menos sensíveis (coeficientes de determinação abaixo de $50 \%$ ). Isso se deve, em parte, à alta variação naturalmente esperada para o tamanho uterino, diretamente associado à quantidade de exsudato especialmente até o sétimo dia pós-parto. Nos períodos subsequentes, aos 14 e 21 dias, houve substancial redução nas medidas observadas, sendo que, aos 28 dias, os valores foram considerados normais para fêmeas lactantes (HAUSER \& BOSTED, 2002). Esses achados corroboram outros estudos, muito embora haja diferenças metodológicas, de raça, ambiente e de manejo entre experimentos. Em clima equatorial, KIRAKOFE (1980) determinou a involução uterina aos 21 dias pós-parto, contrastando com HAYDER \& ALI (2008) que observaram redução no diâmetro uterino somente aos 28 e 35 dias pós-parto em condições subtropicais. Portanto, os achados ultrassonográficos em conjunto com o perfil leucocitário observados no presente estudo sugerem que a involução uterina nas ovelhas nativas do Pantanal ocorre entre 14 e 21 dias.

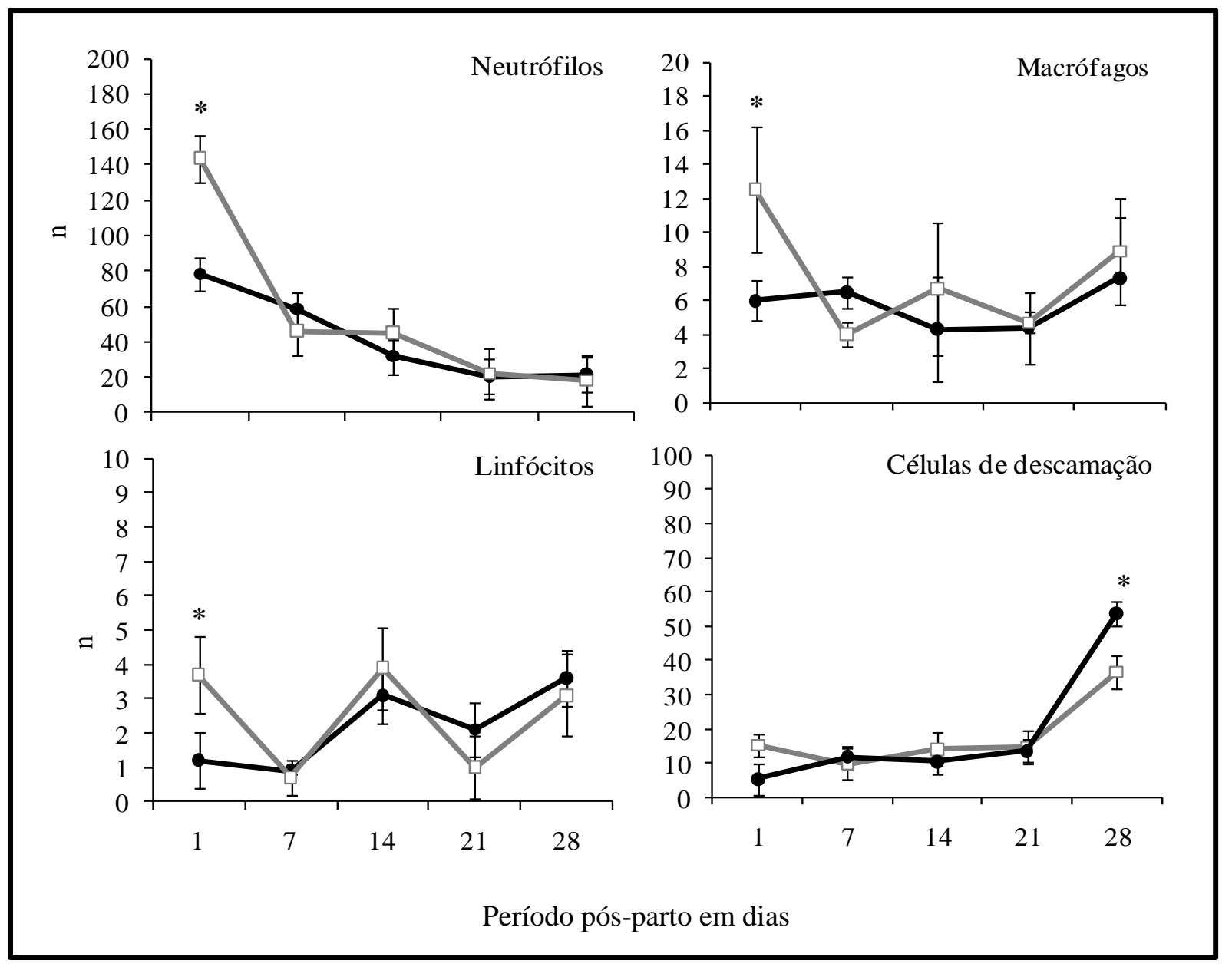

Figura 1. Médias ajustadas ( \pm epm) para células leucocitárias e de descamação observadas nos partos simples $(\bullet)$ e gemelares $(\square)$ de acordo com o período pós-parto em ovelhas nativas do pantanal. 

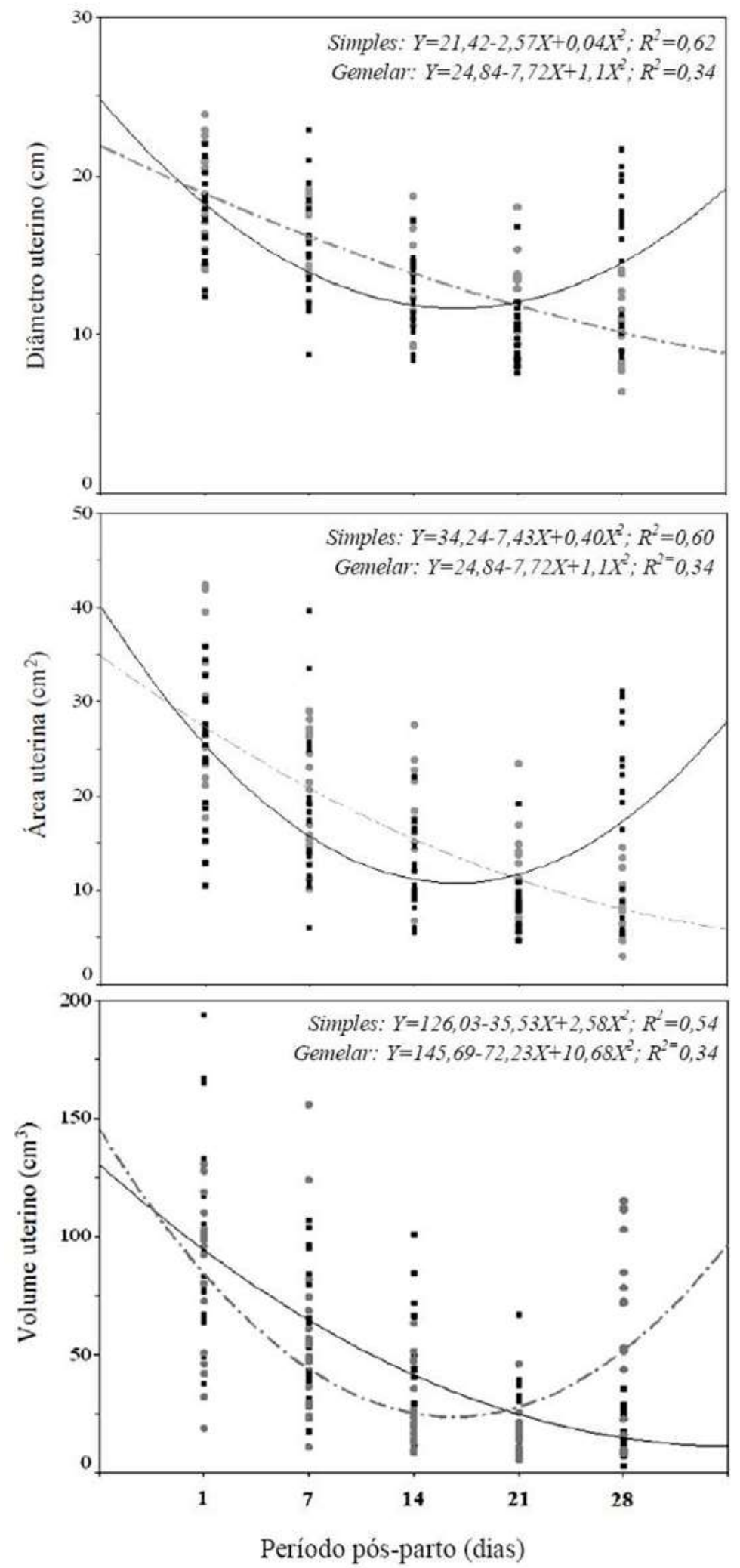

Figura 2. Análise da regressão ${ }^{*}$ para variáveis ultrassonográficas estimadas no periodo pós-parto em ovelhas nativas do pantanal sul-mato-grossense com gestação simples $(-\cdot-)$ e gemelar $(-)$. " Todos os modelos são significativos $(\mathrm{P}<0,001)$. 
Conclui-se que os parâmetros observados ao parto estão de acordo com os reportados por outros estudos e, no geral, trazem subsídios para se conhecer melhor a fisiologia da reprodução nas fêmeas ovinas pantaneiras. A associação do perfil leucocitário cérvico-uterino e da ultrassonografia transretal uterina reúne importantes elementos para prognosticar a função uterina pós-parto. As ovelhas nativas do Pantanal apresentam regeneração uterina satisfatória, permitindo sua utilização em programas de acasalamento intensivo em sistemas tecnificados de criação.

\section{AGRADECIMENTOS}

Os autores agradecem à Médica Veterinária Karina Yurico Naito e à Zootecnista Joycemara Carrera Cunha pela ajuda na condução do experimento; ao Centro Tecnológico de Ovinocultura por ceder o espaço e os animais para a realização do experimento; à FUNDECT/CNPq pela concessão da bolsa de estudo.

\section{REFERÊNCIAS}

BARTLEWSKI, P.M., BEARD, A.P., RAWLINGS, N.C. Ultrasonographic study of ovarian function during early pregnancy and after parturition in the ewe. Theriogenology, v.53, p.673-689, 2000.

DIAS, F.E.F. Sincronização do estro, indução da ovulação e fertilidade de ovelhas deslanadas após tratamento hormonal com gonadotrofina coriônica equiina. Arquivos Brasileiros de Medicina Veterinária e Zootecnia, v.53, p.618-623, 2001.

GARCIA, E.A.C. Estudo técnico-econômico da pecuária bovina de corte do Pantanal Mato-grossense. Corumbá, Embrapa CPAP. (Embrapa Pantanal. Documentos, 4). 1986. 50 p.

GOTTSHALL, S.L., HANSEN, P.J. Regulation of leucocyte sub-populations in the sheep endometrium by progesterone. Immunology. v. 76, p. 636-641, 1992.

GRAY, C.A.; STEWART, M.D.; JOHNSON, G.A.; SPENCER, T.E. Postpartum uterine involution in sheep: histoarchitecture and changes in endometrial gene expression. Reproduction, v.125, p.185-198, 2003.

HAIBEL, G.K. Use of ultrasonography in reproductive management of sheep and goat herds. Veterinary Clinics of North America: Food Animal Practice, v.6, n.3, p.597-613, 1990.

HAUSER, B.; BOSTEDT, H. Ultrasonographic Observations of the Uterine Regression in the Ewe under Different Obstetrical Conditions. Journal Veterinary Medical, v.49, p.511-516, 2002.

HAYDER, M; ALI, A. Factors affecting the postpartum uterine involution and luteal function of sheep in the subtropics. Small Ruminant Research, v.79, p.174-178, 2008.

HINDSON, J. C.; WINTER, A.C. Genital abnormalities, obstetrical problems and birth injuries. In: AITKEN, I.D. Diseases of Sheep. 4. ed. Blackwell Publishing, 2007. p. 75-80.

KEISLER, D. H. Sheep Breeding Strategies. In.: YOUNGQUIST, R.S.; THRELFALL, W.R. Current Therapy in Large Animal Theriogenology. 2. ed. St. Louis: Saunders, Elsevier, 2007. p. 649-661.

KIRACOFE, G.H. Uterine involution: its role in regulating postpartum intervals Journal of Animal Science, v.51, Suppl. 2, p.16-28, 1980.

MORI, R.M.; RIBEIRO, E.L.A.; MIZUBUTI, I.Y.; ROCHA, M.A.; SILVA, L.D.F. Desempenho reprodutivo de ovelhas submetidas a diferentes formas de suplementação alimentar antes e durante a estação de monta. Revista Brasileira de Zootecnia, v.35, p.11221128, 2006.

NAQVI, S.M.K; JOSHI, A.; DAS, G.K.; MITTAL, J.P. Development and application of the ovine reproductive technologies: an Indian experience. Small Ruminant Research, v.39, p.199-208, 2001.

NASAR, A., RAHMAN, A., MEEUSEN, E.N.T., LEE, C.S. Peri-partum changes in the intraepithelial lymphocyte population of sheep interplacentomal endometrium. American Journal of Reproduction and Immunology, V, 47, p. 132-141, 2002.

O'SHEA, J.D.; WRIGHT, P.J. Involution and regeneration of the endometrium following parturition in the ewe. Cell and Tissue Research, v. 236, p. 477-485, 1984.

PENNINGAA, L.; LONGOB, L. D. Ovine Placentome Morphology: Effect of High Altitude, Long-term Hypoxia. Placenta, v.19, p.187-193, 1998.

ROSA, A.N.; ABREU, U.G.P.; SILVA, L.O.C.; NOBRE, P.R.C.; GONDO, A. Pecuária de Corte no Pantanal Brasileiro: Realidade e Perspectivas Futuras de Melhoramento. Corumbá: Embrapa Pantanal, CPAP. (Embrapa Pantanal. Documentos, 93). 2007. 27. Disponível em: http://www.cpap.embrapa.br/publicacoes/online/DOC93.p df. Acesso em: 21 mar 2011.

RUSSEL, A.J.F.; DONEY, J.M.; GUNN, R.G. Subjective assessment of body fat in live sheep. Journal Agricultural Science, v.72, p.451-454, 1969.

SANTOS, S. A.; JULIANO, R. S.; PAIVA, S. R.; ARAÚJO, M. T. B. D.; BERSELli, C. Descrição de sistemas de criação tradicionais de ovinos da Nhecolândia, Pantanal, MS. Corumbá: Embrapa Pantanal, 2010. 5 p. (Embrapa Pantanal. Circular Técnica, 94). Disponível em: <http:www.cpap.embrapa.br/publicacoes/download.php?a rq_pdf=CT94 $>$.Acesso em: 31 dez 2010. 
SHARKEY, S., CALLAN, R. J., MORTIMER, R., KIMBERLING, C. Reproductive techniques in sheep. Veterinary Clinics of North America: Food Animal Practice., v.17, n.2, p.435-455, 2001.

SCHOENAU, L. S. F., PINTO, L. M., PEREIRA, F. T. VOL., SCHOENAU, W., MIGLINO, M. A. Aspectos anatômicos da macro e microvascularização da placenta em ovinos (Ovis aries). Brazilian Journal of Veterinary Research and Animal Science, v.42, p. 405-413, 2005.

SHELDON, I. M., NOAKES, D. E. BAYLISS, M., DOBSON, $\mathrm{H}$ The effect of oestradiol on postpartum uterine involution in sheep. Animal Reproduction Science, v.78, p.57-70, 2003.

McMANUS, C.; PAIVA, S.R.; ARAÚJO, R.O. Genetics and breeding of sheep in Brazil. Revista Brasileira de Zootecnia, v.39, p.236-246, 2010.
THORBURN, G.D., HOLLINGSWORTH, S.A., EOOPER, S.B. The trigger for parturition in sheep: fetal hypothalamus or placenta? Journal of Development Physiology, v.1571, p.1-9, 1991.

TZORA, A., LEONTIDES, L. S., AMIRIDIS, G. S. MANOS, G., FTHENAKIS, G. C. Bacteriological and epidemiological findinds during examination of the uterine content of ewes with retention of fetal membranes. Theriogenology, v.57, p.1809-1817, 2002.

MARIANTE, A.S.; ALBUQUERQUE, M.S.M.; RAMOS, A.F. Criopreservação de recursos genéticos animais brasileiros. Revista Brasileria de Reprodução Animal, v.35, n.2, p.64-68, 2011.

Van WYK, L.C., Van NIEKERK, C.H.; BELONJE, P.C. Involution of the post-partum uterus of the ewe. Journal of the American Veterinary Medical Association, v.43, p.19-26, 1972.

Protocolado em: 10 abr. 2012. Aceito em: 10 abr. 2013. 